\title{
Resenha do livro Wittgenstein's Metaphilosophy, de Paul Horwich, Oxford: Oxford University Press, 2012.
}

Raquel Albieri Krempel - Universidade de São Paulo

A obra de Paul Horwich oferece uma discussão detalhada da metafilosofia de Wittgenstein, isto é, das ideias centrais de Wittgenstein sobre a natureza da filosofia e sobre o papel que lhe cabe, tal como aparecem formuladas nas Investigações Filosóficas (IF). Wittgenstein é famoso por defender que os problemas da filosofia tradicional não são problemas reais. Ele afirma, por exemplo, que, ao contrário dos filósofos tradicionais, "não devemos de modo algum construir teorias. Nada deve ser hipotético em nossas considerações. Toda explicação tem de ser afastada, e em seu lugar entrar apenas a descrição. (...) A filosofia é uma luta contra o enfeitiçamento de nossa inteligência por meio de nossa linguagem" (IF, §109). Além de expor e esclarecer as opiniões metafilosóficas de Wittgenstein, Horwich ensaia sua aplicação na dissolução de problemas filosóficos específicos. Desse modo, diferentemente da maioria dos comentadores, Horwich 
tem o mérito de não se restringir ao comentário do texto. Ele procura não só expor, mas aplicar as ideias de Wittgenstein, lidando com problemas e dialogando com filósofos que não estavam no horizonte do próprio Wittgenstein.

Uma das teses centrais de Horwich é que a metafilosofia de Wittgenstein deve ser tomada como base para a compreensão de seu tratamento de problemas filosóficos específicos. Isso vai contra uma tradição de leitura segundo a qual as observações de Wittgenstein sobre a filosofia são derivadas de sua concepção de significado como uso. O que normalmente se pensa é que Wittgenstein diagnostica o caráter problemático da filosofia tradicional e teórica ("Filosofia-T", como Horwich a denomina) com base na ideia de que ela abandona o uso comum da linguagem. Segundo essa leitura, a linguagem comum é o paradigma de sentido, e dado que a filosofia em geral abandona a linguagem comum, seu discurso estaria fora do campo de sentido. O diagnóstico do caráter problemático da filosofia tradicional dependeria então da concepção de Wittgenstein sobre o significado. Horwich chama a atenção para algumas dificuldades dessa abordagem. Uma delas é a de que os termos apropriados pela filosofia também têm um uso, ainda que muitas vezes não idêntico ao uso comum. Mas o que fundamentaria a ideia de que o simples abandono do uso comum deve levar ao contrassenso? As ciências também alteram o uso de certos termos, sem que sejam condenadas por isso. Se as ciências atribuem novos usos a certos termos, sem perder o estatuto de discurso significativo, por que deveria ser diferente para a filosofia? O ponto de Horwich é o de que a ideia de significado como uso não seria suficiente para desqualificar a filosofia tradicional.

Segundo a interpretação de Horwich, a concepção que Witt- 
genstein tem da filosofia é o que fundamenta o seu tratamento de diversos temas filosóficos, dentre eles o do significado, e não o contrário. Um dos principais problemas da abordagem filosófica tradicional estaria em um tipo de subversão da linguagem comum feita por ela, que consistiria na utilização de analogias linguísticas exageradas e generalizações simplificadoras. O problema não está, portanto, no simples abandono do uso comum de certos termos. De acordo com Horwich, "questões filosóficas tradicionais sobre a natureza dos números, do tempo, do conhecimento, da verdade, da justiça, do livre-arbítrio, e assim por diante, derivam sua fascinação, segundo Wittgenstein, de tensões conceituais (paradoxos) que por sua vez se originam de um exagero perverso de analogias linguísticas" (Horwich, 2013, p. 19). Essas analogias excessivas são acompanhadas por uma ambição de fornecer teorias a priori profundas sobre determinados fenômenos. Inspirado em Wittgenstein, Horwich apresenta a forma geral da ascensão e queda dos problemas filosóficos em oito etapas, que seguem a seguinte ordem: (1) expectativas cientificistas de apresentar uma teoria simples; (2) analogias linguísticas; (3) generalização; (4) idiossincrasia linguística; (5) tensão paradoxal; (6) enfeitiçamento filosófico; (7) teorização filosófica; (8) dissolução terapêutica (Ibid., p. 50-53). Ele ilustra esse procedimento com seis casos de problemas clássicos da filosofia-T: os números, o tempo, a verdade, o bom, o significado e a sensação, esses dois últimos discutidos mais longamente nos capítulos 4 e 6 , respectivamente.

Uma ilustração mais simples dessas etapas é dada quando Horwich as aplica ao problema da natureza dos números. Segundo ele, (1) iniciamos com a expectativa de que deve haver uma teoria simples e profunda sobre os números. (2) Notamos 
que há uma analogia linguística entre os numerais e outros termos singulares. Numerais são usados em sentenças de modo semelhante a termos que se referem a um objeto específico. Por exemplo, a sentença "Netuno é o oitavo planeta do sistema solar" é semelhante à sentença "Sete é um número primo". Nós então generalizamos e concluímos que números devem ser entidades materiais de tipo semelhante aos referentes de termos singulares. Assim como "Netuno" se refere ao oitavo planeta do sistema solar, achamos que também deve haver algo no mundo a que o numeral "sete" se refere. (4) Porém, notamos que podemos formular outros tipos de sentenças sobre números que são bastante diferentes das sentenças que usam termos singulares. Nunca dizemos, por exemplo, algo como "O número 7 é feito de acrílico (ou qualquer outro material)". (5) Chegamos então a uma tensão paradoxal: embora a generalização nos leve a pensar que deve haver um objeto que corresponda ao sete, há certas idiossincrasias linguísticas em nosso discurso sobre os números que tornaria absurda a atribuição a eles de certas propriedades normalmente atribuídas a outros objetos, como extensão ou poder causal. (6) Essas tensões nos levam ao enfeitiçamento filosófico, e passamos a nos perguntar, por exemplo, como pode haver objetos tão estranhos como os números, que tipo de objeto eles podem ser, etc. (7) Daí se seguem diversos tipos de teorias filosóficas que buscam responder a essas perguntas. (8) A última etapa seria a de dissolução do problema.

De acordo com Horwich, a maioria dos problemas filosóficos segue esse padrão. O que os filósofos fazem é exagerar analogias, e com isso nascem pseudoproblemas da forma "como é possível que haja a coisa x?". Um dos erros da filosofia tradicional é que ela procura formular teorias a priori que respondam aos 
pseudoproblemas que nascem desses exageros. Horwich defende a saída de Wittgenstein, que, ao contrário das demais, nega que haja qualquer problema real a ser resolvido. O que há é uma confusão a ser dissolvida. Não há problema, por exemplo, acerca da referência dos números. Não precisamos perguntar se são objetos, onde se encontram, etc. A filosofia tradicional faz essas perguntas porque busca uma visão unificada e simplificada, como aquela da ciência. Wittgenstein, segundo Horwich, nos leva à causa dessas perguntas e dissolve os problemas, freando a tentação de exagerar em analogias.

Além de expor e discutir a concepção metafilosófica de Wittgenstein, o livro contém dois outros debates não inteiramente dedicados a esse tema. No capítulo 2, o foco é o Tractatus e a sua conexão com as IF. No capítulo 5, Horwich trata da interpretação de Kripke sobre significado e linguagem privada em Wittgenstein. Ambos os capítulos prejudicam a unidade do livro, uma vez que o tema da metafilosofia não lhes é central, e, no caso do capítulo sobre Kripke, sequer aparece. Mas além disso, esses capítulos padecem também de outros males. O capítulo 5 discute a já bastante tratada interpretação de Kripke das IF, e não parece trazer nada de essencialmente novo ao debate entre os comentadores. Já o capítulo 2 contraria um dos pontos defendidos por Horwich no início do livro, que é o de que existe uma continuidade entre as obras centrais de Wittgenstein, e por isso não seria adequado traçar a usual distinção entre o primeiro e o segundo Wittgenstein. Nesse capítulo, Horwich elenca uma série de teses defendidas por Wittgenstein no Tractatus e abandonadas nas IF. Tudo aponta, portanto, para uma separação entre as duas fases do pensamento de Wittgenstein, e não para uma continuidade, conforme Horwich pretendia defender. 
Mesmo as partes dedicadas à metafilosofia de Wittgenstein não são isentas de problemas. A proposta audaciosa de Horwich, de escrever sobre um filósofo já muito comentado sem a pretensão de se deter à exegese, pode terminar por desapontar dois tipos de leitores. Por um lado, os especialistas em Wittgenstein sentirão em muitos momentos que Horwich toma uma liberdade excessiva com relação aos textos. Por outro, a exposição de Horwich não é suficiente para convencer os leitores não Wittgensteinianos de que "o feito distintivo de Wittgenstein foi ter apreendido a verdadeira natureza da filosofia" (Horwich, 2003, p. vii). Vejamos então alguns desses problemas.

$$
* * *
$$

A liberdade interpretativa de Horwich tem algumas peculiaridades, que podem fazer com que o livro não seja bem recebido pelos comentadores de Wittgenstein. Uma das que mais chama a atenção é a sistematização das ideias metafilosóficas de Wittgenstein, que é reconhecidamente um filósofo não sistemático, com um estilo característico, muitas vezes obscuro, de escrita e argumentação. Muitos comentadores veem nisso não apenas uma opção de estilo, mas uma consequência necessária de sua atitude anti-teórica com relação à filosofia. Horwich está ciente disso, mas se propõe a defender a ideia controversa de que é possível expor as ideias de Wittgenstein de maneira objetiva e sistemática. A ideia de que os problemas filosóficos passam por oito etapas entre ascensão e queda, por exemplo, pode não agradar os leitores mais conservadores, dado que Wittgenstein não a formula explicitamente. Mas isso não significa que ela não possa ser extraída das IF. Nesse ponto, penso que a interpretação de Horwich é feliz ao fornecer uma caracterização 
clara, e que abertamente não se pretende universal, de como os problemas filosóficos surgem e desaparecem de acordo com Wittgenstein. Embora o próprio filósofo não tenha formulado um esquema semelhante, ele parece ser compatível com as IF. É possível que essa liberdade interpretativa desagrade comentadores mais tradicionais, mas penso que Horwich é bem sucedido ao mostrar que muitas vezes a sistematização das ideias de Wittgenstein é possível, além de desejável.

Um segundo aspecto do livro que pode gerar descontentamento é a escassez de referências a outros comentadores. Quando Horwich apresenta a metafilosofia de Wittgenstein, por exemplo, ele não discute a fundo nada do que já foi escrito sobre o tema. Embora não faltem comentários do próprio Wittgenstein sobre o papel da filosofia, não há acordo entre os seus comentadores sobre qual seria a função principal da filosofia para ele e sobre como interpretar sua prática filosófica. Pensando apenas no Wittgenstein pós-Tractatus, Hutchinson ${ }^{1}$, por exemplo, identifica três tipos de interpretação de sua filosofia: a doutrinal, a elucidativa e a terapêutica. A primeira incluiria os que defendem que Wittgenstein oferece uma teoria do significado como uso; a segunda, aqueles que veem na proposta de elucidação do uso de conceitos o aspecto central de sua obra; a terceira, os que entendem que Wittgenstein propõe uma espécie de terapia filosófica, a qual pretende curar a tentação de formular pseudoproblemas que causariam perturbação intelectual. Horwich oscila entre as duas últimas interpretações, mas não se posiciona explicitamente no debate. No entanto, embora o autor não compare a sua interpretação com a de outros comentadores, ele

${ }^{1}$ P. Hutchinson, "What's the Point of Elucidation?", Metaphilosophy v. 38, n. 5, 2007. 
não deixa de apresentar contribuições importantes para a interpretação de Wittgenstein, como, por exemplo, a ideia de que a metafilosofia de Wittgenstein antecede o tratamento de problemas filosóficos particulares, e que ela não deriva da ideia de que o significado é o uso.

Finalmente, um terceiro aspecto que pode incomodar os comentadores é a falta de referências ao próprio Wittgenstein. Em certos momentos em que fala por Wittgenstein, sem citar nenhuma passagem, Horwich faz afirmações controversas e que dificilmente poderiam ser atribuídas a ele. Por exemplo, em alguns momentos Horwich parece imputar a Wittgenstein um certo desejo de busca pela verdade. Na conclusão do livro, ao responder uma possível objeção de que os resultados a que chega seriam pouco inspiradores e profundos, ele assevera: "talvez, como Wittgenstein sugere, as virtudes da clareza, desmistificação e verdade deveriam ser consideradas suficientemente satisfatórias" (Horwich, 2003, p. 211). Ora, certamente muitos comentadores negariam que a busca pela verdade estivesse no horizonte das Investigações filosóficas, justamente pelo desejo explícito de Wittgenstein de se afastar da filosofia tradicional, que tem como um dos objetivos centrais justamente a busca pela verdade. Observamos em alguns momentos do livro que Horwich parece atribuir a Wittgenstein ambições que seriam típicas da filosofia tradicional que ele pretende combater.

$* * *$

Os leitores céticos quanto à ideia de que Wittgenstein desvendou a verdadeira natureza da filosofia e dissolveu seus problemas tradicionais dificilmente mudarão de opinião com a leitura do livro de Horwich. Segundo o livro, os problemas filosóficos 
tradicionais surgem, em parte, de uma ambição de formular teorias a priori sobre diversos fenômenos que cotidianamente nos parecem simples. Mas Horwich não nos convence de que essa ambição seja inadequada, nem de que o surgimento de tensões paradoxais deva ser um sinal de que os problemas filosóficos não são problemas reais. Horwich diz também que os problemas da filosofia-T são fruto de analogias exageradas. Ele não explica, porém, como se estabelece um limite para as analogias, para que se possa dizer que as analogias filosóficas são exageradas. Mas mesmo que sejam, por que os problemas que nascem de analogias exageradas devem ser considerados pseudoproblemas? A ideia de Horwich parece ser a de que as tensões a que chegamos, a partir das analogias e generalizações, levam a formulações de problemas e de diversas teorias para resolvê-los que são sempre questionáveis, que nunca nos satisfazem. Mas por que o fato de que esses problemas filosóficos surgem de tensões, e o fato de que as tentativas de respondê-los são conflitantes e muitas vezes insatisfatórias, não podem nos levar a concluir que esses são problemas reais e profundos? Embora possa ser verdadeiro que, ao filosofar, muitas vezes exageramos analogias e criamos tensões, essas observações em si mesmas não provam que haja algo de errado nessas atitudes, nem nos problemas filosóficos a que elas dão origem. Em suma, mesmo que os problemas filosóficos surjam da maneira como Horwich (e Wittgenstein) acredita que eles surgem, o livro não deixa claro por que eles são problemas que merecem ser dissolvidos. Embora Horwich procure identificar outros aspectos negativos que estariam na base do pensamento filosófico (cf. seção 2.4 do livro), é questionável o quanto esses aspectos são de fato pressupostos pelas teorias filosóficas. 
Todos esses problemas de certa forma sugerem que Wittgenstein tem uma teoria bastante questionável sobre a natureza da filosofia e sobre como lidar com os problemas da filosofia tradicional. Mas lembremos que, para Wittgenstein, a filosofia deve se ater à mera descrição. Podemos então perguntar: não há uma inconsistência entre a metafilosofia de Wittgenstein e sua prática filosófica? Quando Wittgenstein critica as teorias filosóficas, ele não está também formulando um tipo de teoria? Horwich antecipa esse problema e procura mostrar que, pela maneira como Wittgenstein entende o termo "teoria", não é possível dizer que ele produza uma teoria. "Teoria", para Wittgenstein, "é uma hipótese sobre alguma realidade não evidente (...) que só pode ser conhecida por alguma forma de inferência conjectural" (Horwich, 2003, p. 64). Mas o que deve prevalecer não é o modo como nós usamos o termo "teoria", de acordo com a própria ideia de Wittgenstein de significado como uso? Se for assim, parece que Wittgenstein produz algo a que poderíamos chamar de teoria: ele estipula o que a filosofia deve ser (dissolução de problemas, ou terapia), que ao filosofar fazemos um mau uso da linguagem, a partir do qual surgem problemas que não são problemas reais. Essas não são simples constatações neutras, e podem perfeitamente ser questionadas. Se as observações metafilosóficas de Wittgenstein não são teóricas, mas simples descrições de observações de usos linguísticos, por que são tão controversas? A solução de Horwich é dizer que "não teórico" não é sinônimo de "indisputável". Uma proposta não teórica pode ser disputável, desde que seja possível, depois de algum esforço, reconhecê-la como óbvia. A proposta de Wittgenstein é controversa, mas é potencialmente óbvia, de acordo com Horwich (Ibid., p. 65). Ora, quase tudo é potencialmente 
alguma outra coisa. Horwich apenas afirma que Wittgenstein não formula hipóteses teóricas quando lida com problemas particulares, mas falha na tentativa de provar a suposta obviedade da sua abordagem.

Mesmo quando Horwich deixa de lado as considerações gerais, para tratar de problemas filosóficos específicos, o leitor ainda não sai satisfeito. Cabe mencionar aqui o capítulo 6 , em que discorre mais longamente sobre problemas relacionados à consciência. Ali, o autor pretende mostrar que problemas epistemológicos e metafísicos sobre a consciência nascem de confusões, e não da ignorância, e por isso são pseudoproblemas. Um exemplo de problema epistemológico é o de como podemos ter conhecimento dos estados mentais de outras pessoas. Por mais que na vida comum consideremos que conhecemos os estados mentais de outros, a reflexão filosófica nos leva à ideia de que a vida mental é privada e acessível somente ao próprio sujeito. Nada parece nos impedir de supor, portanto, que outras pessoas tenham qualia invertidos, ou mesmo que não tenham experiências. Para Horwich, é essa imagem dos fenômenos mentais como sendo essencialmente privados que leva a problemas como o dos qualia invertidos.

Segundo Horwich, essa imagem é tentadora porque existe uma semelhança sintática e de uso entre relatos de sensação, como "Tenho dor", e relatos de observação, como "O objeto x tem a propriedade de ser vermelho". De acordo com Horwich, um uso básico de um predicado de observação como "ser vermelho" ocorre quando o aplicamos a objetos vermelhos imediatamente percebidos. Quando não estamos diante de um objeto vermelho, a atribuição de cor se justifica por uma inferência com base nos casos de observação direta (cf. Ibid., p. 186). Exage- 
rando a analogia, no caso da dor pensamos que seu uso básico ocorre quando a atribuímos a nós mesmos, e por isso achamos que a dor é algo que pertence à pessoa que a sente, e que só é acessível a ela própria por introspecção. Achamos então que, no caso de outras pessoas, apenas inferimos que o predicado se aplica a elas, e daí surge o problema do conhecimento de outras mentes. Problemas como esse deixarão de existir, segundo Horwich, se aprendermos a não aplicar o modelo da privacidade mental tão indiscriminadamente. "Dor" e "vermelho", por exemplo, não são tão análogos. Segundo Horwich, o uso básico de "dor" inclui a atribuição a outras pessoas. Essa atribuição não é feita por inferência, com base em nosso próprio sentimento de dor. Não é assim que aprendemos a atribuir dores a outros. Horwich acha que há uma tendência inata em nossa atribuição de dores a outrem. E, para ele, tanto atribuições em primeira como em terceira pessoa são epistemologicamente básicas (Ibid., p. 189-190).

Porém, a solução de Horwich para o problema da atribuição de estados mentais a outros está longe de ser convincente. Em primeiro lugar, porque a noção de "uso básico de um predicado" não é clara, e portanto não é claro que o problema surja por uma identificação incorreta, derivada de uma analogia exagerada, dos usos básicos dos predicados de sensação. Em segundo lugar, mesmo aceitando que nossa atribuição de dores ocorra sem ser inferida da atribuição em nosso próprio caso, disso não se segue que as atribuições de dor a mim mesmo e a outros estejam no mesmo nível epistemológico. Mesmo que seja inata a convicção que temos de que alguém com um osso quebrado sente dor, mesmo que eu atribua dores a outros sem que tenha que inferir a partir de minha própria dor, isso não prova que o 
conhecimento que tenho da dor do outro seja análogo ao conhecimento que tenho da minha própria dor. Nossa convicção de que outros sentem dor pode ser imediata, mas isso não significa que conheçamos as dores dos outros imediatamente. Um argumento em favor da anterioridade epistêmica de nossas próprias sensações é o de que sempre podemos estar enganados sobre os estados mentais de outros, mesmo que tenhamos convicção, ao passo que não podemos estar enganados, por exemplo, quanto a nossa própria dor. Horwich não aborda essa objeção, e por isso não convence seu leitor de que o problema de conhecer os estados mentais de outros seja um pseudoproblema, que tem como base apenas uma analogia exagerada, e não algo mais substancial.

Em suma, o leitor filósofo não especialista em Wittgenstein certamente apreciará a clareza do livro de Horwich, mas é improvável que se convença de que Wittgenstein dissolveu os grandes problemas filosóficos, tal como o problema do conhecimento de outras mentes. Por outro lado, os comentadores que já estão convencidos dos êxitos de Wittgenstein podem apreciar, e eventualmente reproduzir, a maneira sistemática de Horwich de expor e aplicar as suas ideias, ainda que encontrem no livro problemas pontuais. 
